\title{
Untersuchungen über Cetacea.
}

\author{
III. \\ Über die Perikardialfliussigkeit des Seiwals.
}

Von

\section{Makoto Sudzuki.}

(鉿 木 掅)

(Aus dem medizinisch-chemischen Institut der Universität zu

Sendai, wnter Leitung von Prof. Katsuji Inouye.)

Bei den meisten serösen Flüssigkeiten sind die Angaben über ihre Beschaffenheit und Zusammensetzung nicht zahlreich zu finden; insbesondere mangelt es uns an Kenntnis von den Normalen, die wohl für die Aufklärung ihrer Natur und Entstehung von Belang sein soll. Geeignet diese Lücke zu erfüllen, sind die Flüssigkeiten in den serösen Höhlen der Wale, welche man leicht in zur genaueren Untersuchung ausreichenden Mengen erhalten kann.

Die vorliegende Mitteilung enthält die Resultate der Analysen der Perikardialflüssigkeit von Seiwal, Balaenoptera borealis Less.

Die Perikardialflüssigkeit des Seiwals ist klar, nahezu farblos, von klebriger Beschaffenheit (rel. Viskosit. n. Determann=1,4) und frei von morphotischen Bestandteilen. Sie gerinnt nicht freiwillig. Sie besitzt schwach alkalische Reaktion gegen Lackmuspapier. $P_{\mathrm{H}}=7,1-$ 7,6 bei $25^{\circ}$. Ihr spezifisches Gewicht liegt zwischen 1,010 und 1,017. Die Gefrierpunktserniedrigung beträgt $0,69-0.70^{\circ}$. Joly e $t^{1)}$ hat eine kryoskopische Untersuchung von Perikardialflüssigkeit eines grossen Tümmlers unternommen und den Wert von 0,8 erhalten.

" Der Eiweissgehalt ist, nach Scherer bestimmt, niedriger als Angaben beim Menschen.

Nach $\mathrm{K} \ddot{u} \mathrm{z} \mathrm{z}^{2)}$ enthält das Herzbeutelflüssigkeit von gesunden Ochsen

1) F. J o l yet, Sociéte de Biologie, 54 (1902), 293.

2) C. K ül z, Zeitschr. f. Biologie, 32 (1895), 252. 
d-Milchsïure. Ungeführ $200 \mathrm{ccm}$ Flüssigkeit eines Seiwals wurden in bekannter Weise darauf untersucht; der Verdampfungsrückstand des Ätherextrakts zeigte deutlich Milchsäurereaktion. Aber es ist noch nicht entschieden, ob es sich hier um Fleischmilsüure handelt, oder aber um Gährungsmilchsäure.

Zur Zuckerbestimmung wurde die Flüssigkeit nach dem Verfahren von Abeles rom Eiweiss befreit und darauf nach $\mathrm{Pavy}^{1)}$ titriert.

Der Gehalt an Extraktivstuffen wurde in dem nach Folin und Den is ${ }^{2}$ durch Methylalkohol und Chlorzink enteiweissten Filtrat bestimmt; und zwar Harnstoff nach der Ureasemethods von Nagasaw ${ }^{3}$, Harnsäure nach der kolorimetrischen Methode von Folin-Bogert ${ }^{4}$, Kreatin und Kreatinin nach Folin, und Ammoniak und. Aminosäuren nach Sörensen-Henriques. Der Fettgehalt wurde nach Kumagaw a - Suto bestimmt.

l)ie mittlere Zusammensetzung der normalen Perikardialfüussigkeit des Seiwals geht aus der nachstehenden Tabelle hervor.

Quantitative Zusammensetzung. g per $100 \mathrm{ccm}$.

\begin{tabular}{|c|c|c|}
\hline $\begin{array}{l}\text { Wasser } \\
\text { Trockensubstanz }\end{array}$ & $\begin{array}{r}97,44 \\
2,20\end{array}$ & $\begin{array}{l}-97,80 \\
-\quad 2,56\end{array}$ \\
\hline $\begin{array}{l}\text { Gesamtstickstoff } \\
\text { Eiweiss } \\
\text { Harnstoff } \\
\text { Harnsibre } \\
\text { Kreatin } \\
\text { Kreatinin } \\
\text { Aminosäurenstickstof' } \\
\text { Zucker } \\
\text { Fett } \\
\text { Unverseifbares } \\
\text { Cholesterin } \\
\text { Ammoniak } \\
\text { Chlor } \\
\text { Pliosphorsäureanhydrid } \\
\text { Schwefelsäure } \\
\text { Natriumoxyd } \\
\text { Kaliumoxyd } \\
\text { Kalk } \\
\text { Magnesia } \\
\text { Eisen }\end{array}$ & $\begin{array}{l}0,29 \\
1,08 \\
0,06 \\
0,003 \\
0,0006 \\
0,0031 \\
0,010 \\
0,09 \\
0,07 \\
0,006 \\
\nabla 0 \mathrm{rb} \\
0,003 \\
0,40 \\
0,024 \\
0,05 \\
0,49 \\
0,07 \\
0,01 \\
0,0018 \\
\quad \mathrm{~S}\end{array}$ & $\begin{array}{l}-0,32 \\
-1,15 \\
-0,13 \\
-0,004 \\
6-0,001 \\
1-0,0038 \\
-0,012 \\
-0,10 \\
-0,08 \\
-0,007 \\
\text { anden } \\
-0,007 \\
-0,44 \\
-0,025 \\
-0,06 \\
-0,5 \\
-0,08 \\
-0,011 \\
\text { S- } 0,002 \\
\text { sur }\end{array}$ \\
\hline
\end{tabular}

1) Modifikation von Kumagawa-Suto, Salkowski Festsclirift, 1904, 211.

2) O. Folin u. W. Denis, Jl of Biol. Chem., 11 (1912), 527.

3) S. Nagasawa, Kyoto Igaku Zasshi, Organ d. med. Gesellschaft z. Kyoto, 17 (1920), 701. (jap.)

4) L. J. Bogert, Jl. of Biol. Chem., 31 (1917), 165. 